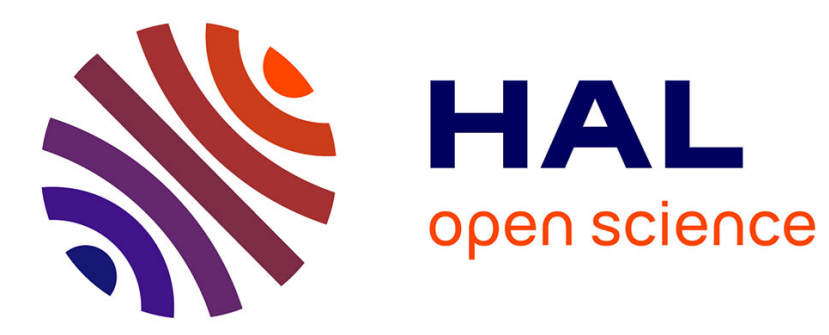

\title{
Mechanical behaviour and damage mechanisms analysis of a flax-fibre reinforced composite by acoustic emission
}

Arthur Monti, Abderrahim El Mahi, Zouhaier Jendli, Laurent Guillaumat

\section{To cite this version:}

Arthur Monti, Abderrahim El Mahi, Zouhaier Jendli, Laurent Guillaumat. Mechanical behaviour and damage mechanisms analysis of a flax-fibre reinforced composite by acoustic emission. Composites Part A: Applied Science and Manufacturing, 2016, 90, pp.100-110. 10.1016/j.compositesa.2016.07.002 . hal-01792109

\section{HAL Id: hal-01792109 \\ https://hal.science/hal-01792109}

Submitted on 4 Feb 2020

HAL is a multi-disciplinary open access archive for the deposit and dissemination of scientific research documents, whether they are published or not. The documents may come from teaching and research institutions in France or abroad, or from public or private research centers.
L'archive ouverte pluridisciplinaire HAL, est destinée au dépôt et à la diffusion de documents scientifiques de niveau recherche, publiés ou non, émanant des établissements d'enseignement et de recherche français ou étrangers, des laboratoires publics ou privés. 


\title{
Mechanical behaviour and damage mechanisms analysis of a flax-fibre reinforced composite by acoustic emission
}

\author{
Arthur Monti ${ }^{\mathrm{a}, *}$, Abderrahim El Mahi ${ }^{\mathrm{a}}$, Zouhaier Jendli $^{\mathrm{b}}$, Laurent Guillaumat ${ }^{\mathrm{c}}$ \\ ${ }^{a}$ LAUM - Laboratoire d'Acoustique de l'Université du Maine, Avenue Olivier Messiaen, 72085 Le Mans Cedex 9, France \\ ${ }^{\mathrm{b}}$ ESTACA'Lab - Pôle Mécanique des Matériaux Composites et Environnement, Parc Universitaire Laval-Changé, Rue Georges Charpak, BP-76121, 53061 Laval Cedex 9, France \\ ${ }^{c}$ LAMPA - Laboratoire Angevin de Mécanique Procédés et innovAtion, Arts et Métiers ParisTech Campus Angers 2, Boulevard du Ronceray, 49035 Angers Cedex 01, France
}

A R T I C L E I N F O

Keywords:

A. Biocomposites

A. Natural fibres

C. Damage mechanics

D. Acoustic emission

\begin{abstract}
A B S T R A C T
This article presents the mechanical characterization of an eco composite consisting of a thermoplastic matrix reinforced by flax fibres. Different configurations of specimens were tested with uniaxial tensile loading and their mechanical behaviours were discussed. Moreover, the acoustic emission technique was used to detect the appearance of damage mechanisms and to follow their evolution. In addition, a list of these mechanisms was established by means of macroscopic and microscopic observations. The acoustic emission records were post processed by the k-means unsupervised pattern recognition algorithm. Depending on the specimen configuration, three or four classes of events were obtained. The acoustic characteristics of these classes were compared. Then, a correlation between these AE events classes and the damage mechanisms observed was proposed. Their effects on the mechanical behaviour of the material were investigated by means of a variable called the Sentry Function.
\end{abstract}

\section{Introduction}

The use of eco composites has increased during the last decade [1]. To face recent ecological challenges, engineers are looking for lighter and greener materials for numerous applications, for example in transportation or sport and leisure industries. Composites reinforced with plant fibres are particularly interesting, especially flax fibres reinforced polymers (FFRP) [2]. Flax fibres exhibit specific properties sometimes better than those of synthetic glass fibres [3]. Their microstructure composed of coaxial layers reinforced by oriented micro fibrils gives them high mechanical strength and stiffness [4]. However, despite these advantages, FFRP tend to be still limited to non structural applications. Several technological limitations still have to be broken. Among them, the understanding and anticipation of micro damage mechanisms leading to the failure of the material. Moreover, the use of thermosetting matrices makes eco composites hard to recycle, reducing their environmental performances. In addition, thermoplastic matrices often depend upon manufacturing processes, such as thermo compression, which can damage the fibres due to the temperature required to melt the polymers. Moreover, thermoplastics are often incompatible with the manufacturing of large structures at small scales using processes such as resin transfer moulding (RTM) or resin liquid infusion (LRI).

Acoustic emission (AE) technique has been often used for the identification and characterization of micro failure mechanisms in composites [5,6]. Micro structural changes in materials release strain energy, resulting in the propagation of acoustic waves. These signals are recorded by sensors fixed on the material. Then, features are deduced from these acoustic bursts. Among them, temporal features are often used, such as amplitudes, energies and rise times $[7,8]$. Moreover, acoustic emission works performed on glass or carbon fibre reinforced composites often involve mixed time-frequency analyses [9-12]. AE technique has also been used for several natural fibre composites with different reinforcements and matrices [13-16] and at different observation scales. Rhomany et al. [17] used it during a tensile test performed on a flax fibre bundle to isolate the damage mechanisms related to technical fibres. They noticed three damage mechanisms. The lowest amplitudes were caused by the longitudinal separation of the elementary fibres inside the bundle. Then, events produced by fibre micro-cracking were recorded, followed by the complete failure of elementary fibres leading to the breakage of the entire bundle. Some authors also performed AE monitored tests on pure resin specimens. Several phenomena can be distinguished, such as matrix cracking and matrix/matrix friction [18]. At the composite scale, amplitudes between 40 and $60 \mathrm{~dB}$ are usually attributed to 
Table 1

$\mathrm{AE}$ characteristics of the main damage mechanisms in eco composites according to the literature.

\begin{tabular}{|c|c|c|c|}
\hline Failure mechanism & Material & Characteristics & Ref. \\
\hline Matrix cracking & $\begin{array}{l}\text { Flax/LPET } \\
\text { Birch/Polyethylene } \\
\text { PP/Hemp and Chenovene } \\
\text { Flax/Epoxy }\end{array}$ & $\begin{array}{l}\text { Amplitude }[40-50] \mathrm{dB} \\
\text { Amplitude }[35-45] \mathrm{dB} \text {, duration }[1-80] \mathrm{ms} \\
\text { Amplitude }[40-60] \mathrm{dB} \\
\text { Amplitude }[42-60] \mathrm{dB}\end{array}$ & $\begin{array}{l}{[19]} \\
{[18]} \\
{[15]} \\
{[14]}\end{array}$ \\
\hline Matrix-Matrix friction & Flax/LPET & Amplitude [40-55] dB, duration [20-120] ms & [19] \\
\hline Fibre-matrix debonding & $\begin{array}{l}\text { Flax/LPET } \\
\text { PP/Hemp and Chenovene } \\
\text { Flax/Epoxy }\end{array}$ & $\begin{array}{l}\text { Amplitude }[45-60] \mathrm{dB} \\
\text { Amplitude }[45-60] \mathrm{dB} \text {, duration }[50-200] \mathrm{ms} \\
\text { Amplitude }[60-65] \mathrm{dB} \\
\text { Amplitude }[60-70] \mathrm{dB}\end{array}$ & $\begin{array}{l}{[19]} \\
{[15]} \\
{[14]}\end{array}$ \\
\hline Fibre-matrix friction & Flax/LPET & Amplitude [55-85] dB, duration [100-600] ms & [19] \\
\hline Fibre pull-out & Flax/LPET & Amplitude [60-80] dB & [19] \\
\hline Fibre cracking & Flax fibre bundle & Amplitude [35-60] dB & [17] \\
\hline Fibre breakage & $\begin{array}{l}\text { Flax fibre bundle } \\
\text { Flax/LPET } \\
\text { PP/Hemp and Chenovene } \\
\text { Flax/Epoxy }\end{array}$ & $\begin{array}{l}\text { Amplitude }>60 \mathrm{~dB} \\
\text { Amplitude [80-96] dB } \\
\text { Amplitude [85-95] dB } \\
\text { Amplitude [70-100] dB }\end{array}$ & $\begin{array}{l}{[17]} \\
{[19]} \\
{[15]} \\
{[14]}\end{array}$ \\
\hline
\end{tabular}

matrix cracking. Fibre/matrix debonding is often attributed to amplitudes between 45 and $70 \mathrm{~dB}$. Of course, the values of these intervals depend on the kind of fibres and matrix used. Friction phenomena (matrix/matrix or matrix/fibre) are sometimes ignored or included in the previous categories. Aslan [19] distinguished these events in the case of flax/LPET composites. Fibre failures are attributed to the events exhibiting the highest amplitudes and energies. They generally occur just before complete failure of the specimen. Data concerning fibre pull-out or fibre cracking is scarcer. In fact, these mechanisms are harder to isolate from the others. However, they are often attributed to amplitudes between fibre/matrix debonding and fibre breakage. In particular cases, especially for crossed-ply composites, the $\mathrm{AE}$ technique can be used to detect delamination [20]. However, this global phenomenon contains several damage mechanisms such as fibre pull-out and cracking, or fibre/matrix friction. Despite an increasing number of multi parametric studies, it is worth emphasizing that amplitude remains the classification feature the most often discussed in literature for natural fibre composites. Data concerning features such as duration and energy are scarcer [18,19]. Table 1 summarizes the values obtained by five different sources for different kinds of eco composites.

The present paper reports the production and the mechanical characterization of an eco composite made of a thermoplastic matrix reinforced by flax fibres. The matrix is a recent liquid thermoplastic resin initially developed for RTM processes, allowing the use of the liquid resin infusion technique. The composite obtained was subjected to quasi static tensile loading to investigate its mechanical behaviour. Moreover, the tensile tests were monitored by acoustic emission. The main objective was to identify the failure mechanisms occurring under the load, and to correlate their effects with the tensile behaviour of the material.

\section{Material and experimental procedure}

\subsection{Materials and manufacturing}

The reinforcement used in this work is a layer of unidirectional fibres held together without any twist. For this product (FlaxTape $\odot$ ) manufactured by LINEO [21], the fibres are sprayed with a mist of water that reactivates their external layer of pectin cement. This ensures the cohesion of the parallel fibres, and allows the handling of the layer without misaligning or separating them. For this study, the surface mass of the Flax Tape was $200 \mathrm{~g} \cdot \mathrm{m}^{-2}$.
The matrix is a thermoplastic liquid resin (Elium RT 150@) manufactured by ARKEMA. This acrylic resin is activated by peroxide (CH50x). It can be processed by RTM or LRI as a thermosetting resin, whereas the composite obtained after polymerization is thermoplastic.

Composite plates are processed by liquid resin infusion. A flat mould is initially prepared with a release agent. Unidirectional flax fibre sheets are manually cut from the reinforcement roll. The flax sheets are dried at $110^{\circ} \mathrm{C}$ for one hour in a ventilated oven. The temperature and cycle have been determined to remove enough water without degrading too much the mechanical properties of the fibres [22]. After drying, the layers of flax are superposed on the mould in the desired stacking sequence. They are then covered with a peel ply and an infusion mesh made of a perforated film and a grid which increases the permeability of the medium. This stack of dry material is then covered by an impermeable flexible film, fixed to the mould by an adhesive sealer. This sealed bag contains a resin inlet, initially closed, and a flexible pipe connected to a vacuum pump. Maximum vacuum is applied and maintained for one hour at least to allow the degassing of the stacked plies. Then, the pressure is set to -0.5 bars, and the resin inlet is opened. The resin is distributed through the infusion mesh and impregnates the fibres. When the layers are totally impregnated, the resin inlet is closed and the vacuum is maintained until the end of polymerization.

Three types of unidirectional specimens composed of five flax plies were prepared for the tensile tests, with fibre directions of $90^{\circ}, 45^{\circ}$ and $0^{\circ}$. They were labelled UD-90, UD-45 and UD-0. Moreover, two kinds of crossed-ply specimens labelled CR-(0/90) and $\mathrm{CR}-(+45 /-45)$ were manufactured with stacking sequences of $[0 / 90 / 0 / 90 / 0]$ and $[+45 /-45 /+45 /-45 /+45]$. These specimens were chosen to favour damage mechanisms in particular configurations. UD-90 specimens were assumed to favour matrix cracking and fibre-matrix interface failure. UD-45 specimens were assumed to show a higher number of fibre-matrix debonding, due to a shear loading configuration. Fibre cracks were assumed to be detected just before the failure of specimens UD-0. Due to inter-laminar shear stress, delamination was expected to occur for CR-(0/90) specimen, a failure mechanism emphasized in CR- $(+45 /-45)$ configuration. Several samples were extracted from these different composite plates to determine their density. Their masses were measured with a weigh scale to the nearest $10^{-4} \mathrm{~g}$. Their volumes were measured by weighing the samples immerged on water at room temperature based on the Archimedes principle. 


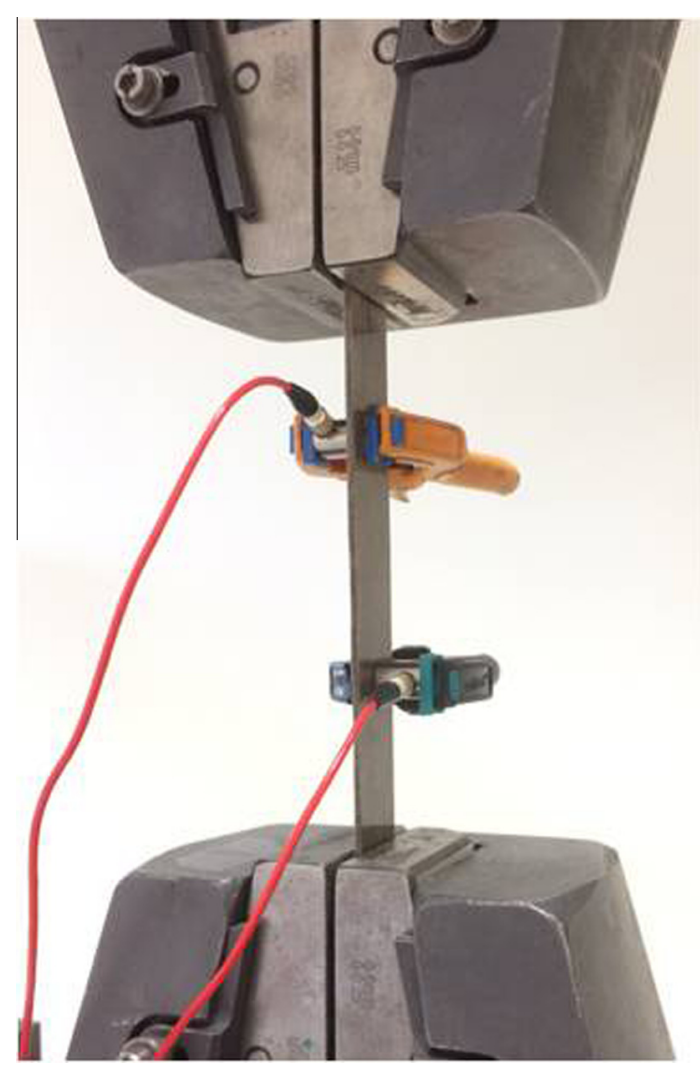

Fig. 1. Composite specimen with acoustic emission sensors. (For interpretation of the references to color in this figure legend, the reader is referred to the web version of this article.)

\subsection{Experimental setup}

Five rectangular $(25 \mathrm{~mm} \times 250 \mathrm{~mm})$ samples of each type of specimen were tested under uniaxial loading, according to the standard test method ASTM D3039/D3039M [23]. The tests were carried out with a tensile machine equipped with a $100 \mathrm{kN}$ load cell. The strains in the tensile direction were measured by mean of an extensometer with a gauge length of $50 \mathrm{~mm}$ (Fig. 1a). The strains in the transverse direction were measured with $5 \mathrm{~mm}$ strain gauges. The tests were performed at room temperature with a displacement rate of $1 \mathrm{~mm} \cdot \mathrm{min}^{-1}$. In addition, cyclic loading tests were performed on UD-0 specimens to emphasize the different behaviour phases of this specific configuration. The applied load was incremented by $20 \mathrm{MPa}$ per cycle. For the acoustic emission records, another set of 5 samples from each series of specimens were also tested in uniaxial tensile loading. Two sensors with a bandwidth of $100 \mathrm{kHz}$ to $1 \mathrm{MHz}$, provided by Euro Physical Acoustics were clamped to the specimens (Fig. 1b). A coupling agent was used between the sensors and the material. AE signals were registered with a sampling frequency of $5 \mathrm{MHz}$. Two preamplifiers with a $40 \mathrm{~dB}$ gain were used to amplify the signals. After preliminary trials, the acquisition parameters employed were set to the following values: $\mathrm{PDT}=50 \mu \mathrm{s}, \mathrm{HDT}=100 \mu \mathrm{s}$ and $\mathrm{HLT}=200 \mu \mathrm{s}$. Pencil lead break tests were performed before each tensile test, to verify that the system was functioning properly, and to define an amplitude acquisition threshold (fixed at $38 \mathrm{~dB}$ ) to filter acoustic signals coming from the test machine or other external sources. Only events recorded in the gauge length delimited by the two sensors were recorded.

For each category of specimens broken in traction, macroscopic and microscopic analyses of the failure modes and mechanisms were performed. Macroscopic analysis was done by visual inspec- tion of the broken specimen, and with a binocular magnifier with a 10-power magnification. The aim was to identify the existence or absence of the main damage mechanisms such as delamination or fibre pull-out on the different types of specimen. The failure profiles of the specimens were also analyzed by scanning electron microscopy (SEM), in order to detect smaller damage mechanisms. In addition, microscopic sections were prepared with pieces of material extracted from an untested UD-0 reference specimen and from a UD-0 specimen loaded to $50 \%$ of the maximum load.

\section{Results}

\subsection{Mechanical properties}

The fibre volume fraction of the material was calculated from the values of the masses and volumes of five $400 \mathrm{~mm}^{2}$ samples extracted from several UD plates. The fibre weight fraction $\varphi_{p}$ was first estimated by:

$\varphi_{p}=\frac{N S \rho_{s}}{m_{c}}$

with $N$ the number of UD flax plies used, $S$ the surface of the sample, $\rho_{s}$ the surface mass of the reinforcement $\left(200 \mathrm{~g} \cdot \mathrm{m}^{2}\right)$ and $m_{c}$ the mass of the sample.

The fibre volume fraction $\varphi_{\mathrm{v}}$ was then calculated by:

$$
\frac{1}{\varphi_{v}}=\frac{\rho_{r}}{\rho_{m}}\left(\frac{1}{\varphi_{p}}-1\right)+1
$$

where $\rho_{\mathrm{m}}$ is the density of the matrix equal to 1.29 and $\rho_{\mathrm{r}}$ the density of the fibre between 1.45 [21] and 1.55 [24]. The value of $\varphi_{v}$ is uncertain as the average density of flax fibres may depends on the location on the composite plate. Moreover, the surface mass of reinforcement is also locally scattered. Thus, according to Eqs. (1) and (2), $\varphi_{v}$ was measured between $35 \%$ and $40 \%$ for all the specimens.

The void content of the material was then calculated by comparing the measured density of the composite and its theoretical density calculated from the volume fraction of fibre and assuming that the volume fraction of matrix $\varphi_{m}$ is: $\varphi_{m}=1-\varphi_{p}$. Then the void fraction of the material was given by:

$$
V_{v}=1-\rho_{c}\left(\left(\frac{\varphi_{p}}{\rho_{r}}\right)+\left(\frac{1-\varphi_{p}}{\rho_{m}}\right)\right)
$$

where $\rho_{c}$ is the density of the composite. Regarding the uncertainty on $\varphi_{v}$ and $\rho_{r}$, the void content was measured (according to Eq. (3)) between $2.5 \%$ and $7.5 \%$.

Fig. 2(b) presents typical stress/strain curves obtained by static monotonic tensile tests performed for every kind of specimen. Samples UD-0 and CR-(0/90) (containing fibre aligned with the tensile direction) exhibit a short linear elastic domain followed by a non linear part. This kind of behaviour is not observed for traditional composites. However, it has already been reported for long Natural Fibre Reinforced Polymers in [24,25]. The initial yield point, occurring for a very low deformation level and resulting in an important loss of stiffness is visible on the stress/strain curves. Results of cyclic loading tests performed on UD-0 specimens are reported in Fig. 3a. They revealed the existence of this "knee" visible on the stress/strain curve occurring at a strain level of $0.11 \%$. After this yield point corresponding to a stress level of approximately $25 \mathrm{MPa}$, the static stress/strain curve appears to be quasi linear. The apparent stiffness even increases slightly. This phenomenon was confirmed by the analysis of the evolution of the tangent modulus presented in Fig. 3b. The tangent modulus was defined at each point of deformation $\varepsilon_{i}$ as the slope of the linear fitting of the stress-strain curve in the interval $\left[\varepsilon_{i}-2.5 \times 10^{-4}\right.$; 


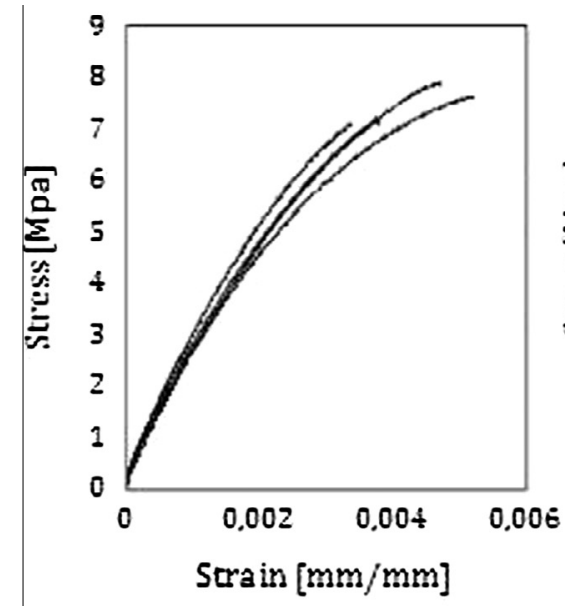

(a)

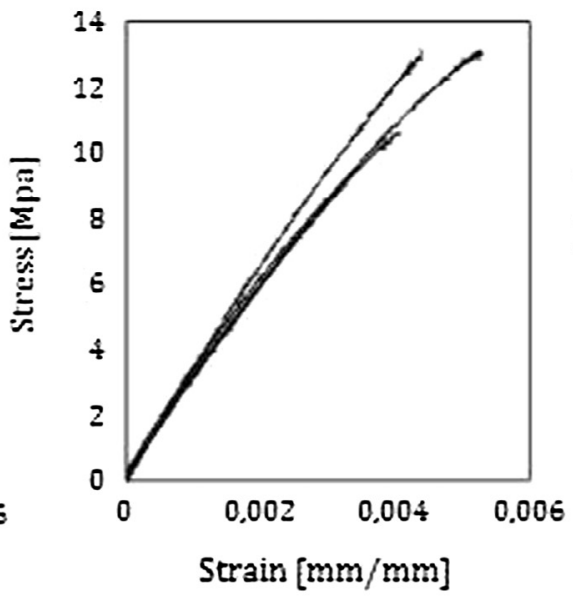

(b)

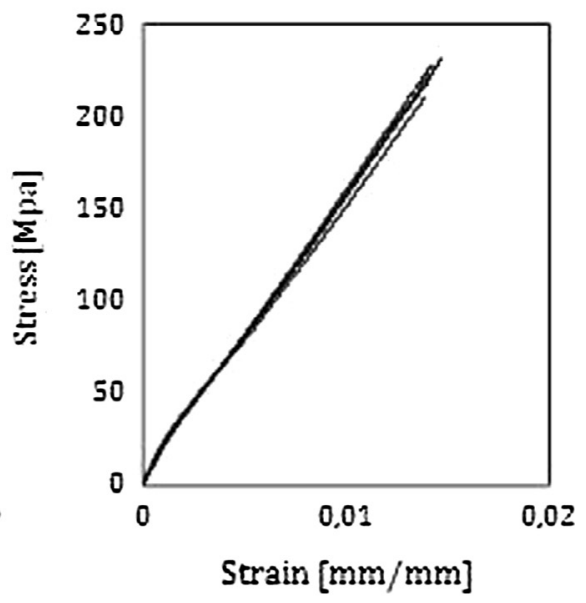

(c)



(d)

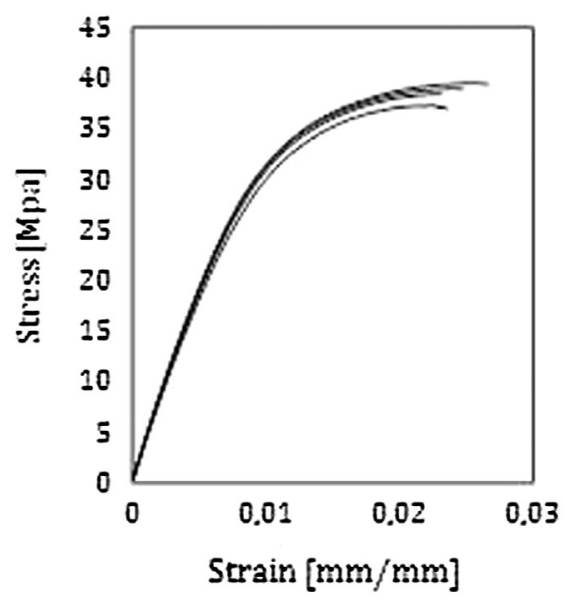

(e)

Fig. 2. Monotonic tensile test stress-strain curves for specimens: (a) UD-90, (b) UD-45, (c) UD-0, (d) CR-(0/90) and (e) CR-(+45/-45).

$\left.\varepsilon_{i}+2.5 \times 10^{-4}\right]$. Thus, the strain dependency of the stiffness was studied for every loading phase of the quasi static cyclic test. Every cycle induces an initial loss of stiffness which confirms that the "knee" mentioned for monotonic static tests exists for every loading phase. As a consequence, this knee cannot be attributed only to damage mechanisms (such as matrix cracking or fibre/matrix debonding), as it appears to be (at least partly) reversible. It may also be a consequence of the non linear behaviour of the flax fibres themselves. This behaviour has been noticed by several mechanical analyses performed on single flax fibres, and is attributed to the yielding and viscous behaviour of the lignin and amorphous cellulose of the fibre because of shear stresses in the cell walls $[4,26]$. However, damage mechanisms occur at every loading phase. As long as the strains never exceed $0.3-0.4 \%$, every cycle induce a reduction of the initial stiffness of the next cycle. This is no longer observed for cycles that load the specimen above a strain of $0.3 \%$. The initial stiffness of the successive cycles starts to increase, until it reaches more than $10 \%$ of its initial value. This phenomenon seems to indicate that stiffening mechanisms occur. It has recently been observed by Shah [25] for a flax fibre composite with an epoxy matrix. To explain this phenomenon, one of the state of the art hypotheses $[25,26]$ is that the reorientation of cellulose microfibrils is driven through a "stick-slip" mechanism. Shear stress inside the cell wall can provoke a viscous flow of the matrix surrounding the fibrils, followed by a lock-in phenomenon associated with immediate bond re-formation in the fibril's new position. As a consequence, the fibre's stiffness can be increased.

However, every cycle also creates irreversible damage mechanisms as the applied load increases. This is confirmed by the loss of stiffness visible as a decrease of the slope at the end of every stress-strain curve (Fig. 3a). The shift of the curves as the number of cycle increases indicates that plastic strains are created with every successive loading phase beyond the elastic domain. As a conclusion, every cycle induces an initial loss of stiffness and a final stiffness decrease. Between these two parts, a stiffness stabilization phase is observed, during which the tangent modulus slightly increases for the last cycles. At the fibre scale, this stiffness increase can be attributed to the partly irreversible reorientation of the cellulose microfibrils described previously. Moreover, the amorphous cellulose is suspected to crystallize under shear stress [26,27]. Therefore, this fibre specific behaviour cannot be observed at the composite scale unless the fibre matrix interface is good. Moreover, no tension was applied on the fibres while positioning them during the manufacturing phase. As a consequence, macro reorientation of the fibres may occur above a certain level of strain. The plastic deformation of the matrix may help to make this phenomenon partly irreversible. However, additional tests should be performed to verify this hypothesis. 

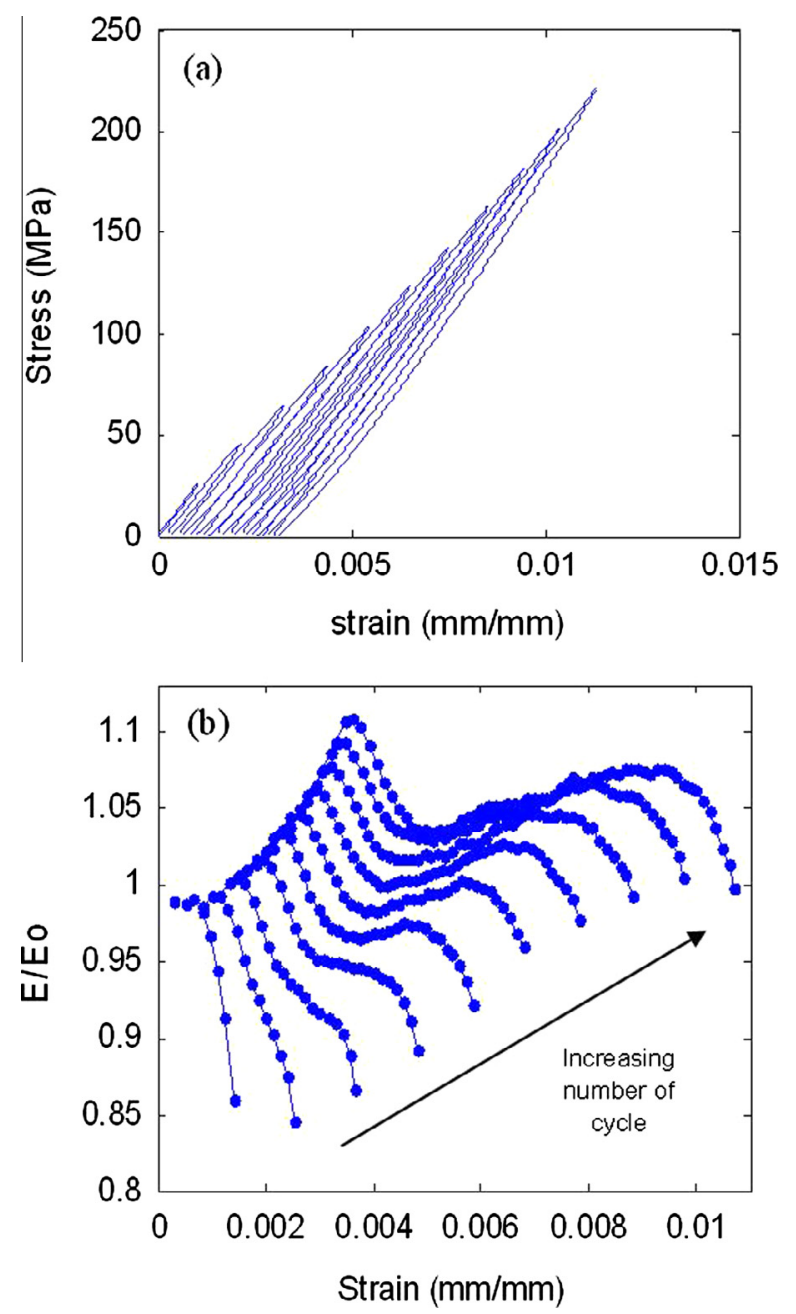

Fig. 3. Quasi static cyclic tests performed on UD $0^{\circ}$ specimen. (a) Stress/strain curves and (b) stiffness versus strain for every cycle. (For interpretation of the references to color in this figure legend, the reader is referred to the web version of this article.)

Table 2

Mechanical properties of the UD composite.

\begin{tabular}{lllllll}
\hline \multicolumn{2}{l}{ Elastic properties } & & & \multicolumn{3}{l}{ Strength properties } \\
\cline { 5 - 6 } Name & Value & Stand. dev. & & Name & Value & Stand. dev. \\
\hline$E_{L}(\mathrm{GPa})$ & 23.3 & 1.16 & & $\sigma_{L}(\mathrm{MPa})$ & 225 & 8.85 \\
$E_{T}(\mathrm{GPa})$ & 3.22 & 0.12 & & $\sigma_{T}(\mathrm{MPa})$ & 7.51 & 0.29 \\
$v_{L T}$ & 0.35 & 0.01 & & $v_{T L}$ & 0.07 & 0.01 \\
$E_{45}(\mathrm{GPa})$ & 3.64 & 0.14 & & $\sigma_{45}(\mathrm{MPa})$ & 38.5 & 0.35 \\
$G_{L T}(\mathrm{GPa})$ & 1.53 & 0.16 & & $\sigma_{L T}(\mathrm{MPa})$ & 17.7 & 2.13 \\
\hline
\end{tabular}

Regarding the previous considerations, the tensile properties of the unidirectional composites were measured in the initial linear elastic domain. They are summarized in Table 2. Shear modulus $G_{L T}$ and strength $\sigma_{L T}$ were deduced from tests performed on CR$(+45 /-45)$ specimens using Eqs. (4) and (5) [28], which give the Young modulus $E_{\theta}$ and failure stress $\sigma_{\theta}$ of an UD composite corresponding to a fibre orientation $\theta$, with respect to its transverse ( $\mathrm{T}$ ) and shear (LT) properties.

$\frac{1}{E_{\theta}}=\frac{\cos (\theta)^{4}}{E_{L}}+\frac{\sin (\theta)^{4}}{E_{T}}+\left(\frac{1}{G_{L T}}-\frac{2 v_{L T}}{E_{L}}\right) \sin (\theta)^{2} \cos (\theta)^{2}$

$\sigma_{\theta}=\left(\left(\frac{\sin ^{2}(\theta)}{\sigma_{T}}\right)^{2}+\left(\frac{\sin (\theta) \cos (\theta)}{\sigma_{L T}}\right)^{2}\right)^{-\frac{1}{2}}$
The values of the longitudinal modulus $E_{L}$ corresponds closely to its theoretical value given by a mixture law (Eq. (6)) regarding the volume fractions of fibres $\varphi_{f}^{v}$ and matrix $\varphi_{m}^{v}$ and their respective moduli $E_{f}=60 \mathrm{GPa}$ [19] and $E_{m}=3.3 \mathrm{GPa}$ (supplier data).

$E_{L}=\varphi_{f}^{v} E_{f}+\varphi_{m}^{v} E_{m}$

\subsection{Microscopic analyses}

Fig. 4 presents the five kinds of specimen after breakage. At a macroscopic scale, the observations of these failure profiles provided brought a lot of information. Specimen UD-90 failed linearly along the transverse direction whereas specimen UD-45 presented a failure front at $45^{\circ}$ with respect to the loading direction. For specimen UD-0 specimen, initial cracks a few millimetres long could be noticed, followed by a propagation of long cracks along the tensile axis. For all these unidirectional specimens, several pulled-out fibres were noticeable even for UD-90. Specimens CR-(0/90) failed perpendicularly with respect to the loading direction. Successive plies with $0^{\circ}$ and $90^{\circ}$ directions appeared to be delaminated along a few millimetres only (Fig. 4). On the other hand, specimens CR- $(+45 /-45)$ failed along two axes orientated at $+45^{\circ}$ and $-45^{\circ}$ with respect to the loading axis. Failed specimens exhibited delaminated plies over several millimetres, visible on Fig. 4e.

These observations were completed by several microscopic analyses (Fig. 5). First, a micrographic section of a reference untested UD specimen was observed (Fig. $5 a-c$ ). Label 1 shows that some bundles are not bonded to the matrix. This is confirmed by a close up presented in (Fig. 5b, label 1), which reveals the existence of layers of organic material that surround the technical fibres. Several cracks can be observed around them. It is hard to know if this interfacial debonding is due to the preparation of the micrographs (specimen cutting and/or polishing) or if it existed before. On the other hand, well separated elementary fibres seem to be correctly bonded to the matrix (Fig. 5a, label 2). On this reference specimen, porosities appeared to be rare. Some $100 \mu \mathrm{m}$ long porosities were observed close to the material side which was directly in contact with the mould (Fig. 5c.). However, the material core contained a surprisingly limited number of porosities (10-20 $\mu \mathrm{m}$ ) (Fig. 5d, label 1 ). On the UD specimen loaded to $50 \%$ of the breaking load, the number of fibre-matrix interface debonding appeared to be slightly higher (Fig. 5d). In addition, lots of unbounded interfaces were observed between adjacent elementary fibres inside bundles (Fig. 5d label 2 and Fig. 5e label 1), where the matrix could not impregnate the fibres due to their very high density. This may explain the low strength properties of the UD-90 and UD-45 specimens. Some matrix cracks could also be observed but were quite hard to detect (Fig. 5e label 2). Most of the time, they appear to be propagations of initial cracks at the interface of bundles and matrix.

SEM analyses of failure profiles revealed other damage mechanisms. Some well separated fibres broken very close to the matrix were observed on UD-0, CR- $(0 / 90)$ and CR- $(+45 /-45)$ specimens (Fig. $5 \mathrm{f}$ label 1 ), indicating that the fibre-matrix interface is good for elementary fibres. Several pulled-out fibres were observed on every kind of specimen, especially on CR-(0/90) and on CR-(+45/-45) (Fig. 5f label 2 and Fig. 5g label 1). In this last case, the length of delamination was very great. Moreover, some of the pulled out fibres were damaged. Transverse cracks could be noticed (Fig. 5h label 1), especially on kink band areas. Peeled fibres were also observed (Fig. 5h label 2), as well as torn fibres (Fig. 5i). This indicates that complex failure mechanisms can be observed at the fibre scale. 


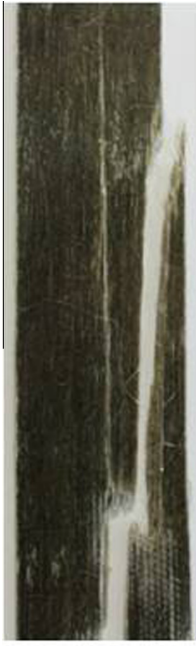

(a)

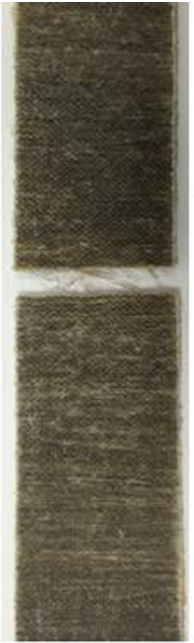

(b)

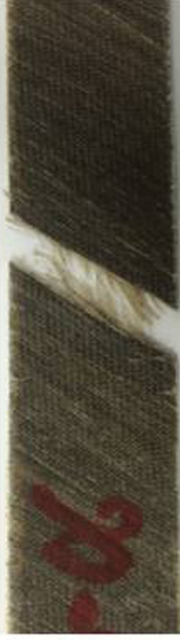

(c)

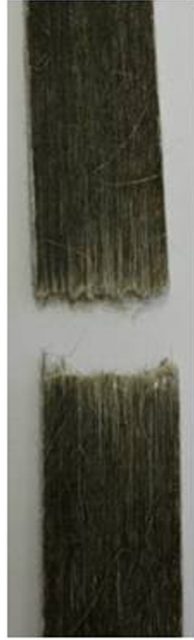

(d)

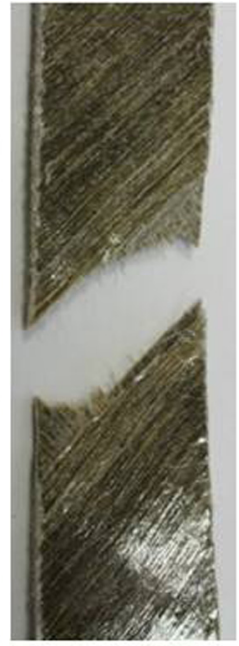

(e)

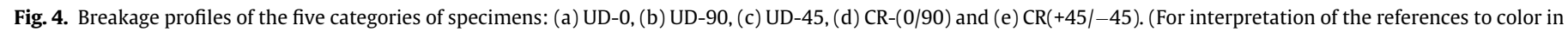
this figure legend, the reader is referred to the web version of this article.)

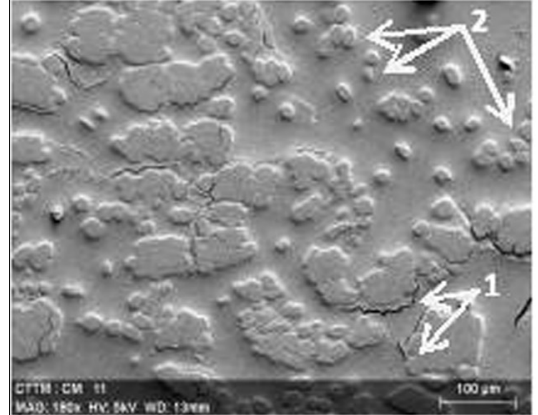

(a)

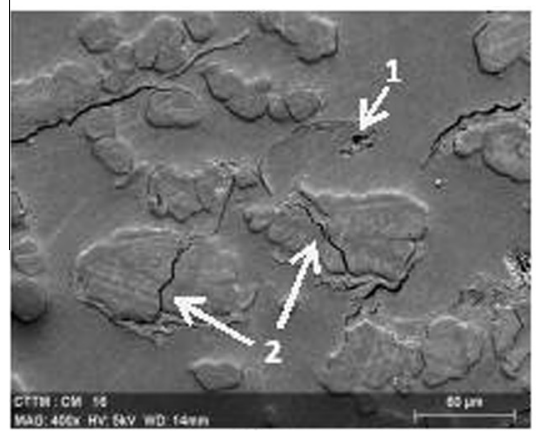

(d)

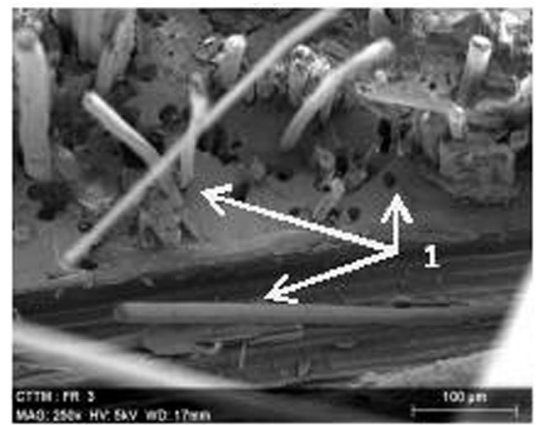

(g)

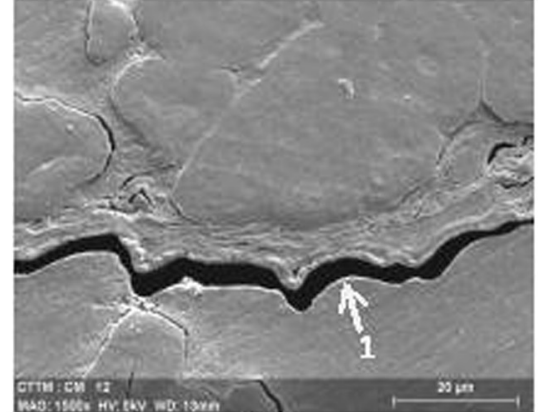

(b)

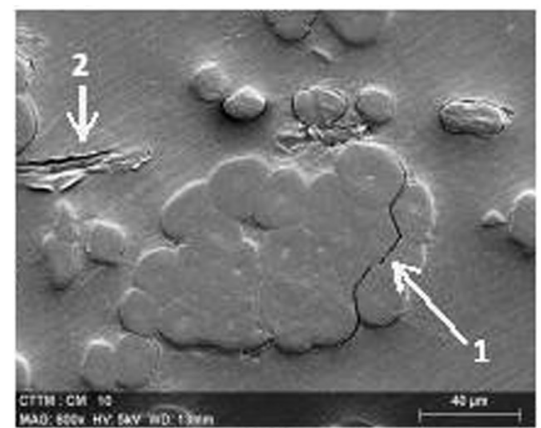

(e)



(h)

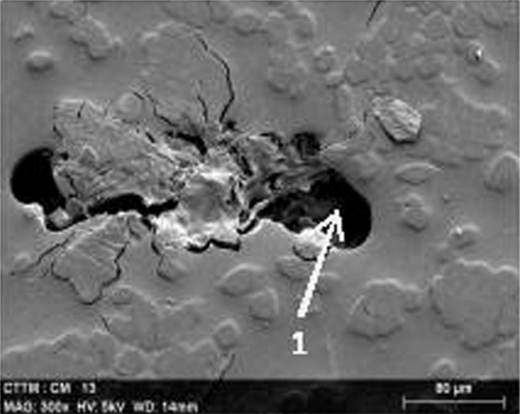

(c)

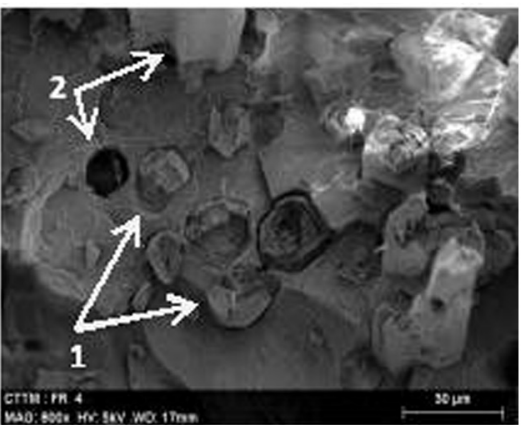

(f)

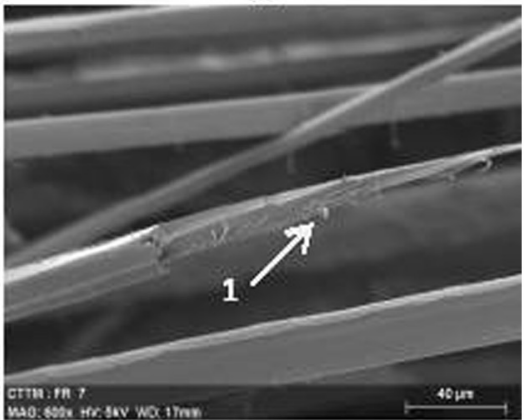

(i)

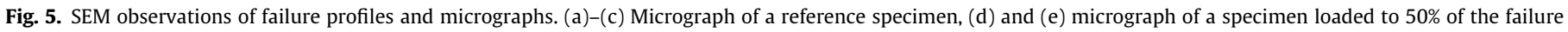
load and (f)-(i) SEM views of different breakage profiles. 


\subsection{AE data processing}

The acoustic emission data was processed with NOESIS and MATLAB software. Five temporal parameters of the acoustic signals were selected for the classification of the data sets: amplitude, rise time, duration, absolute energy and number of counts to peak. After multiple initial trials, these parameters have proved to allow a good repeatability of the data clustering. They are illustrated in Fig. 6.

The K-mean algorithm [29] was used for the unsupervised pattern recognition. This algorithm aims to separate a set of $n$ events into an optimal number of $\mathrm{k}$ clusters in which each event belongs to the cluster with the nearest mean. First, the data sets were normalized by the following transformation:

$\forall i \in \Omega_{p}, \quad p \in \mathcal{F}: z_{i}=\frac{x_{i}-m_{x_{p}}}{\sigma_{x_{p}}}$

where $x_{i}$ is the ith event of a set of data $\Omega_{p}$ related to the acoustic feature $p, m_{x_{p}}$ and $\sigma_{x_{p}}$ the average value and the standard deviation of $\Omega_{p}$, and $\mathcal{F}$ the set of features chosen for the classification. The k-mean algorithm was applied with Euclidian distance and a random initial partitioning. It was repeated several times with 1000 iterations each time, for a range of class varying from 2 to 7 . An average value of the Davies and Bouldin criterion $R_{i j}(D \& B)$ [30] was calculated after each application of the algorithm. This criterion is given by:

$R_{i j}(D \& B)=\frac{1}{k} \sum_{i=1}^{n} \max _{i}\left(\frac{d_{i}+d_{j}}{d_{i j}}\right)$

with $k$ the number of selected classes, $d_{i}$ the average distance in the $\mathrm{i}_{\text {th }}$ class, $d_{j}$ the average distance in the $\mathrm{j}_{\mathrm{th}}$ class, and $d_{i j}$ the average distance between classes $i$ and $j$. The best number of class $k$ is the one that minimizes the average value of $R_{i j}(D \& B)$.

To complete this unsupervised pattern recognition approach, a global variable was used to focus on the relationship between the $\mathrm{AE}$ activity and the mechanical behaviour of the specimen. The Sentry Function (SF) was chosen because it combines both mechanical and acoustic energy information [31-33]. This function is defined by:

$f(x)=\ln \left(\frac{E_{s}(x)}{E_{a}(x)}\right)$

where $E_{s}$ and $E_{a}$ are the strain energy and cumulative acoustic energy of the material with respect to the variable $x$ (usually the strain or displacement). This function can present five noticeable

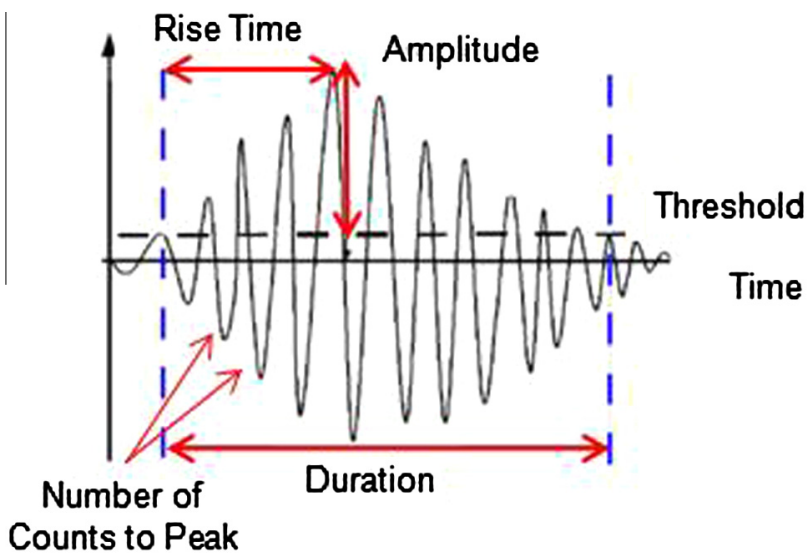

Fig. 6. Acoustic emission burst features. (For interpretation of the references to color in this figure legend, the reader is referred to the web version of this article.)



Fig. 7. Possible behaviour of the Sentry Function.

domains (Fig. 7). An increasing area, noted $\mathrm{PI}(\mathrm{x})$, a sudden drop function $\operatorname{PII}(\mathrm{x})$, a constant function $\operatorname{PIII}(\mathrm{x})$, a decreasing part $\operatorname{PIV}(\mathrm{x})$ and a bottom-up one $\mathrm{BU}(\mathrm{x})$. Phase PI corresponds to the mechanical energy storing phase, which increases continuously while the material remains undamaged. Then the cumulative acoustic energy increases with the number of failure mechanisms, provoking a decrease of the PI slope. For major damage events, a high quantity of mechanical energy suddenly converted into acoustic energy is visible as a PII part. The slope of the Sentry Function becomes zero or less when the material has totally lost its ability to store mechanical energy. This moment is visible by a PIII or PIV function. A BU curve indicates that an event (such as strengthening) suddenly induced a new mechanical energy storage capacity of the material.

\subsection{Classification results}

The application of the classification methodology described before returned the following results. Three classes were obtained for the specimens UD-90 and UD-45, whereas four classes were observed for specimens UD-0, CR-(0/90) and CR-(+45/-45). Fig. 8a presents the amplitudes of these $\mathrm{AE}$ classes with respect to the time, superposed with the evolution of the applied load. Amplitude seems to properly separate these classes for specimens UD-90 and UD-45. However, for the three other categories involving a larger number of events, the very small areas of intersection between the different classes in the amplitude/time domain confirms that the choice of a multi-parameter approach was appropriate. Fig. $8 \mathrm{~b}$ presents the cumulative number of hits for each class with respect to time. This is a good indication of the chronology and evolution of the acoustic events. For example, for specimens UD-90, UD-45 and CR-(+45/45), the number of hits in classes A, B and $C$ increases progressively until the failure of the specimen. However, for specimens of type UD-0 and CR-(0/90), a significant increase of every class is observed just before failure.

Fig. $8 c$ presents the evolution of the Sentry Function (SF) and the applied load with respect to time for the five types of specimens. Specimens UD-90 and UD-45 exhibit a very similar behaviour. The Sentry Function presents successive PI and PII slopes indicating that lots of sudden failure mechanisms occurred. The slopes of the PI parts progressively decrease, and become zero and negative, indicating that the specimen lost quickly its ability to store mechanical energy, until its overall failure. Specimen UD-0 exhibits a more complex behaviour. Three parts can be distinguished. The first one corresponds to a drastic global decrease of the function. It can be attributed to the sudden appearance of lots of acoustic events just after the yield point. The second part is composed of successive PI and PII parts. This indicates that lots of sudden damage mechanisms occur and convert quantities of mechanical energy into acoustic energy. However, the SF increases globally. This confirms that the failure mechanisms frequency decreases and allows the storage of more mechanical energy. The 

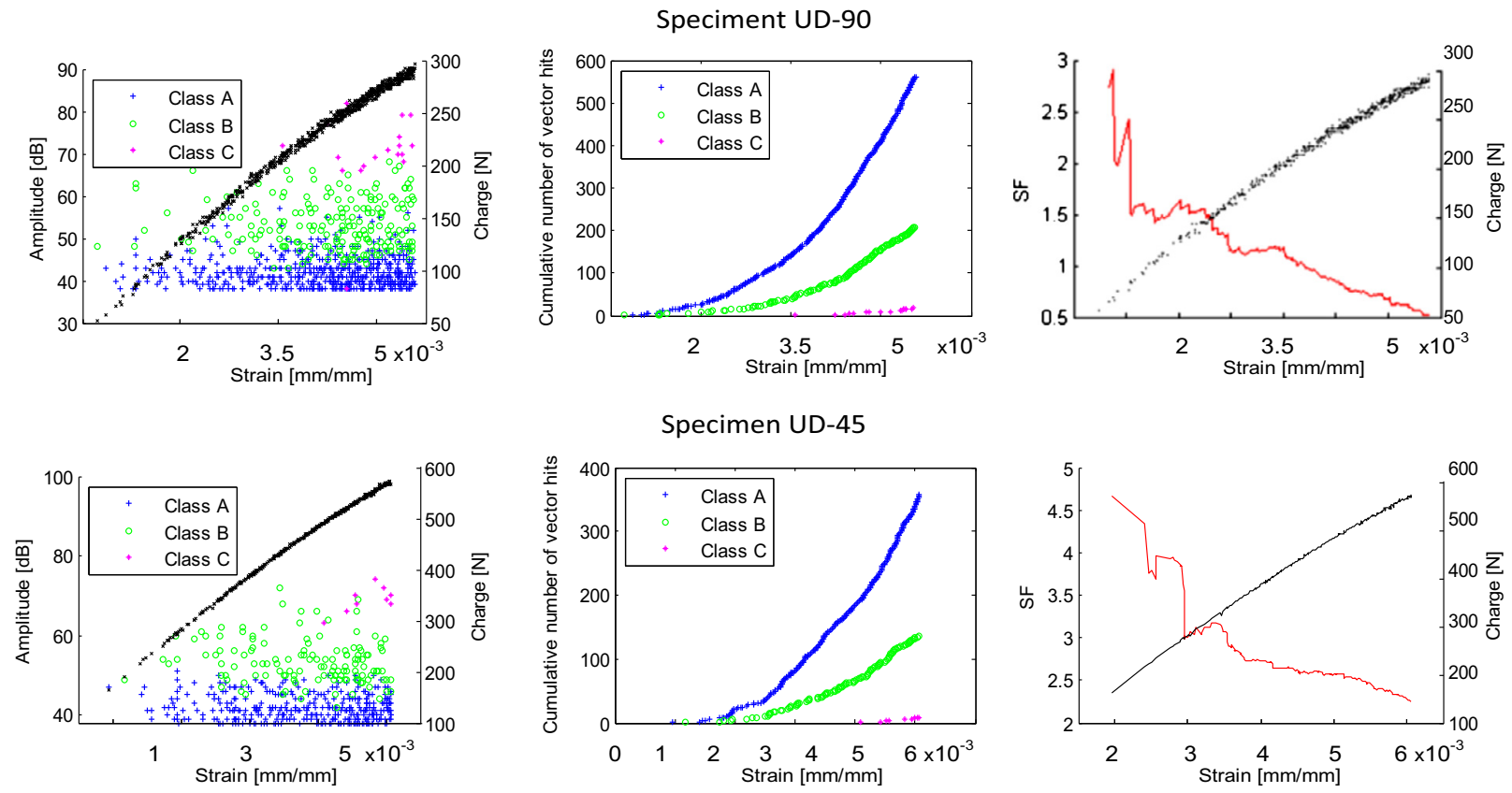

Specimen UD-45
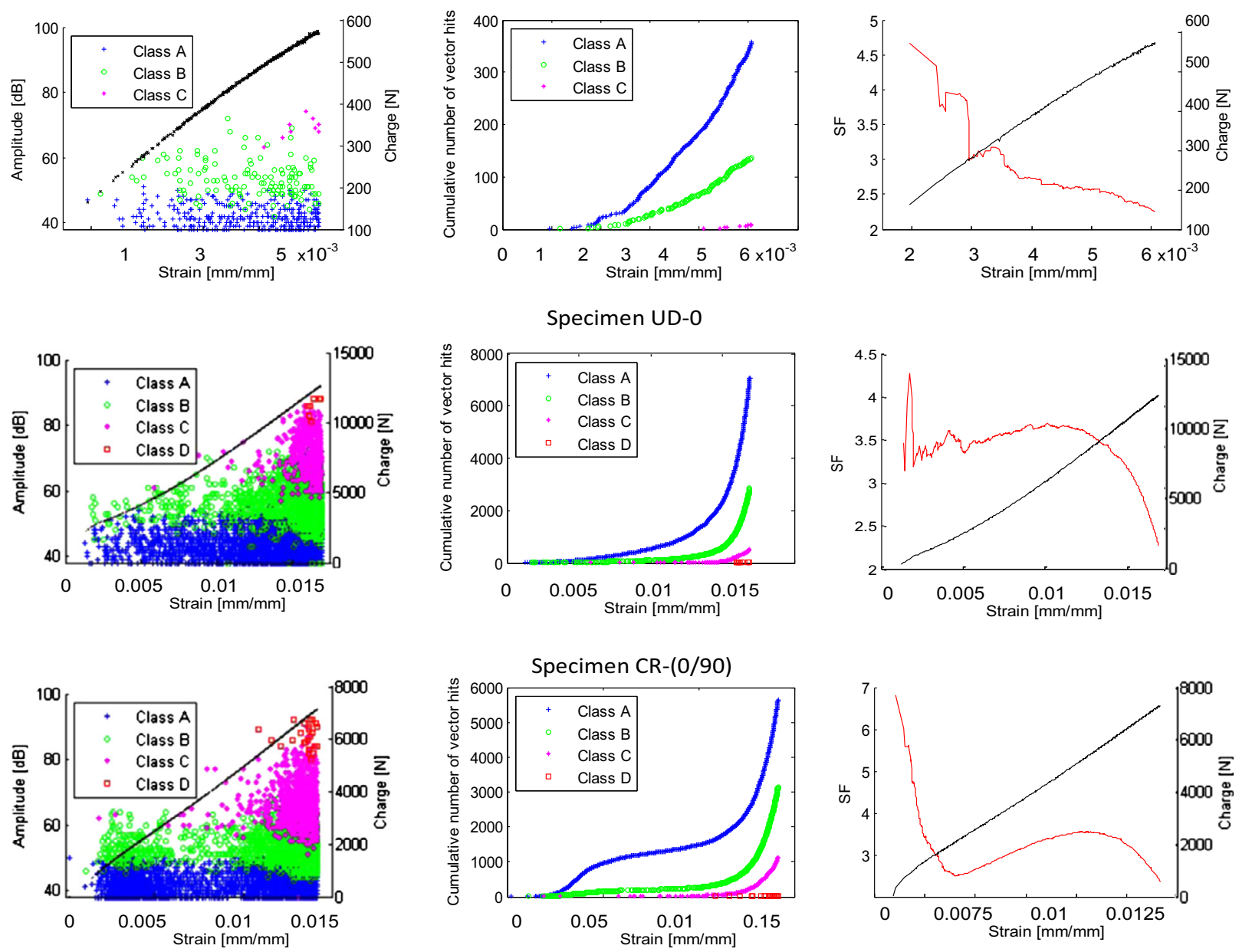

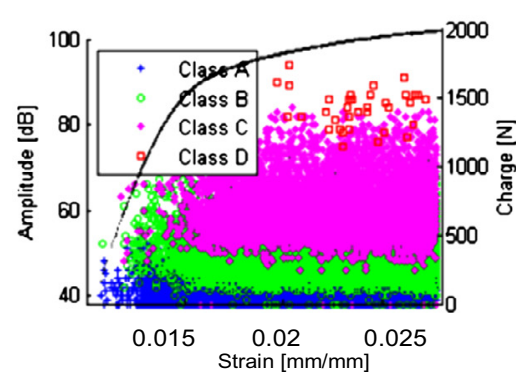

(a)

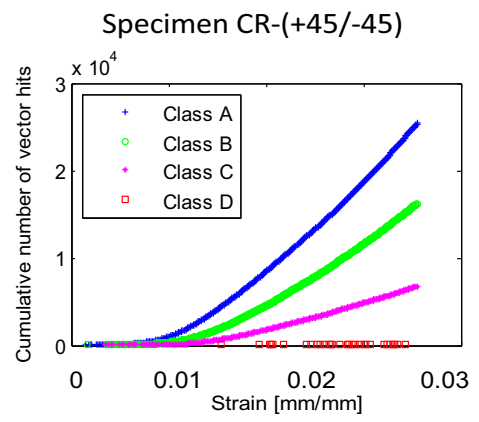

(b)



(c)

Fig. 8. AE classification and analysis results. (a) Amplitude of the events and applied load with respect to strain, (b) chronology of apparition of the different classes and (c) sentry function and applied load with respect to strain. (For interpretation of the references to color in this figure legend, the reader is referred to the web version of this article.) 




(a)

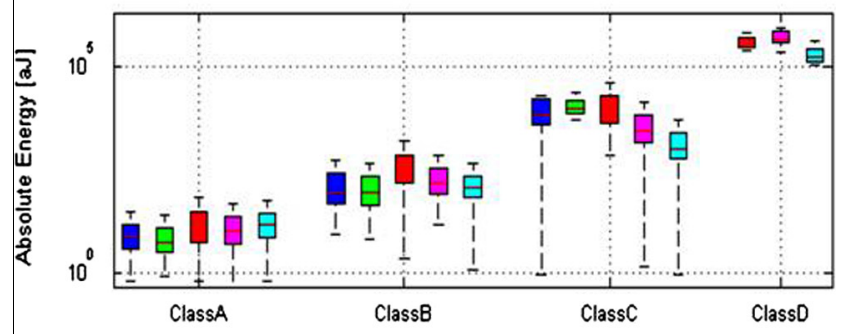

(b)

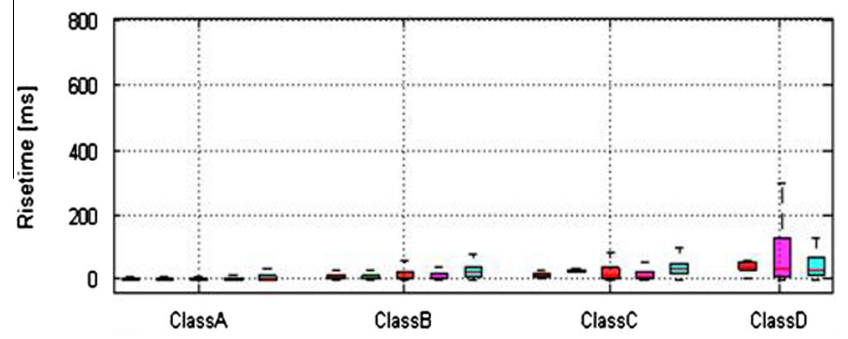

(c)

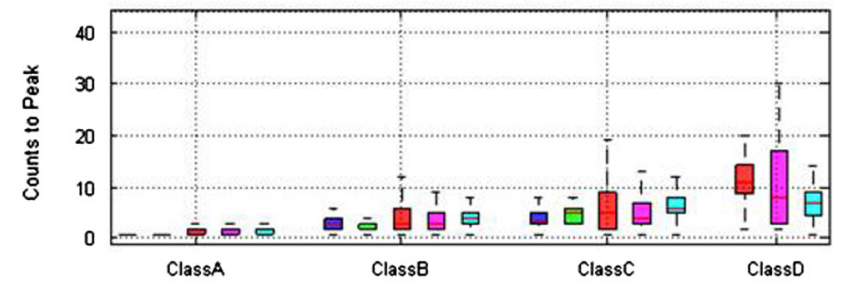

(d)

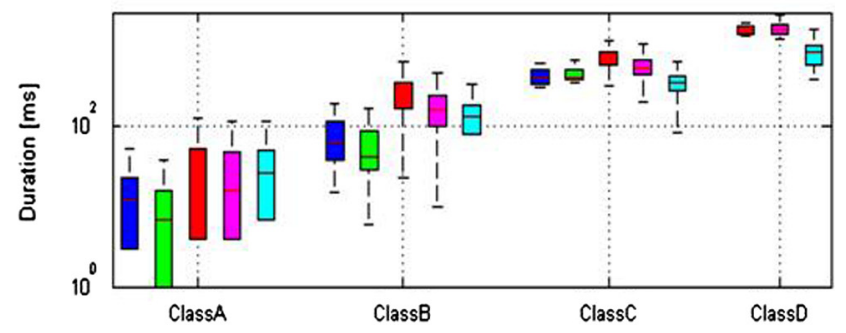

(e)

Fig. 9. Statistical dispersion of the AE classes for every classification feature. (a) Amplitude, (b) absolute energy, (c) rise time, (d) counts to peak and (e) duration. (For interpretation of the references to color in this figure legend, the reader is referred to the web version of this article.)

third part of the curves corresponds to a decrease in the Sentry Function (PIV type). It corresponds to the occurrence of events of class $C$ and $D$. The appearance of these events correspond to a dramatic increase in the number of vector hits in all other classes (Fig. $8 \mathrm{~b}$ ), and leads to the failure of the specimen. The same three areas can be observed for specimen CR-(0/90), even if the higher number of recorded events makes the SF curve appear smoother. It is worth emphasizing that the inflexion points of the Sentry Function correspond to the variation in stiffness mentioned previ- ously for specimens UD-0 and CR-(0/90). It is possible to identify the initial loss of stiffness of the composite, and the phase during which the stiffness of the material increases slightly while the damage mechanisms frequency decreases. At the end of the tensile tests, the number of failure mechanisms is very high. The fall of the Sentry Function clearly corresponds to the occurrence of class $C$ and $\mathrm{D}$ mechanisms that lead to the failure of the specimen.

The $\mathrm{AE}$ classes shown previously were obtained by an unsupervised pattern recognition algorithm, which means that they constitute the best separation of the data regarding mathematical considerations, without really taking physics into account. As a consequence, to see if the class named " $A$ " in a specific configuration was the same as the one also called " $A$ " in the four other cases, the average properties of the classes of every specimen in every configuration were compared, as well as their statistical spread. Fig. 9 shows box and whiskers plots of the four AE classes for the five types of specimens tested and according to the five classification features chosen. The borders of the box correspond to the first quartile $q_{1}$ and the third quartile $q_{3}$. The second quartile (or median) is the line cutting through the box. The whiskers indicate the lower and upper values located in the interval $\left[q_{1}-1.5\right.$ $\left.\left(q_{3}-q_{1}\right), q_{3}+1.5\left(q_{3}-q_{1}\right)\right]$. Values outside this interval, considered as outliers, were not printed. It is clear that classes A and B present quite similar statistical characteristics for every specimen configuration and for every classification parameter. Class D presents more spread regarding number of counts to peak and rise time. These two features are very sensitive to undesired concatenated signals which may not have been totally filtered by the timing acquisition parameters previously defined. As a consequence, extreme values are probably responsible for this abnormal dispersion. AE class $\mathrm{C}$ presents more differences between the different specimens and features. However, this spread may have been emphasized by the huge difference in the number of vector hits between the different specimens. Regarding the different loading configurations, this may also indicate that class $C$ cannot be attributed to a unique damage mechanism. Fig. 10 presents a comparison of the average values of the selected features in the five specimen configurations. The star diagrams clearly show that acoustic signatures can be attributed to each class. The average properties for each specimen are indeed very similar, despite the differences noticed previously regarding their statistical dispersion.

\section{Discussion}

Regarding the previous observations, it appears that the number of damage mechanisms listed previously does not match with the number of acoustic emission classes. As a consequence, the AE classes may not correspond to single failure mechanisms. However, it is possible to attribute groups of events to the different classes.

Whatever the specimen configuration, classes A and B appear simultaneously. Moreover, Fig. 8a corresponding to specimen UD-0 shows that as long as the force applied does not exceed $50 \%$ of the failure load, only class A and B exist. In addition, Fig. $5 d$ and e reveal an increase of matrix cracking and fibrematrix debonding on micrograph sections corresponding to an UD-0 specimen loaded to $50 \%$ of its failure load. This indicates that class A and B can be attributed to matrix cracking and fibre/matrix debonding mechanisms. According to literature and as mentioned in Table 1 , matrix cracking usually causes AE bursts with amplitudes lower than those of fibre/matrix debonding. As a consequence, it can be attributed to class A. In addition, signals of class B presents higher amplitudes and energies, but also shorter durations and higher rise times. These burst shapes correspond 

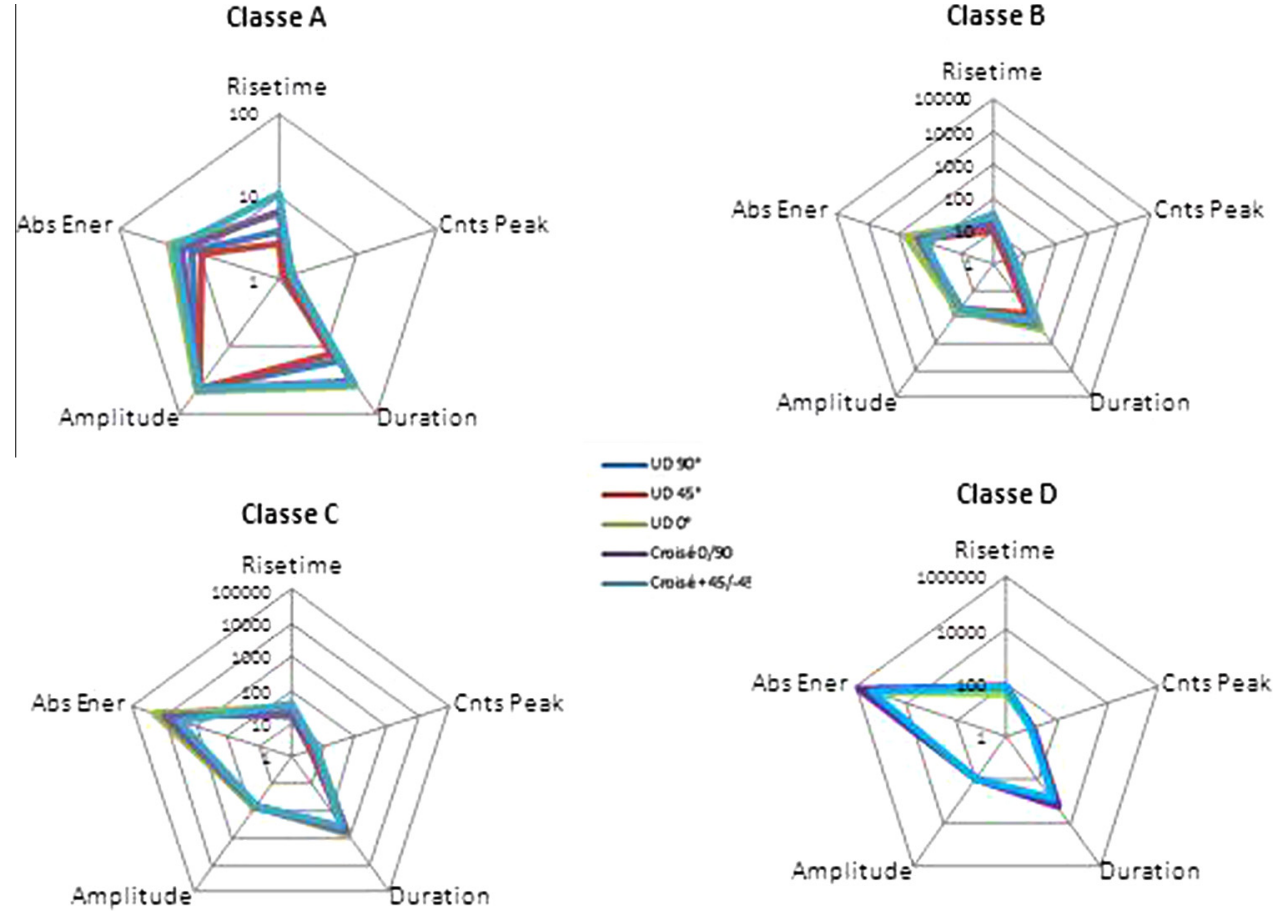

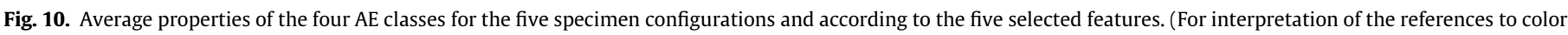
in this figure legend, the reader is referred to the web version of this article.)

to typical pulsed signals emitted by fibre/matrix debonding in traditional GFRP [7]. Thus, class B can be attributed to fibre/matrix debonding mechanisms. The evolution of the number of hits for classes A and B is very similar, particularly for UD-90, UD-45 and CR-(+45/-45) specimens. This remark confirms the observations made in Fig. 5d, which reveals that most of the matrix cracks are prolongations of interfacial failures. Moreover, the analyses of the Sentry Functions for specimens UD-90 and UD-45 show that classes A and B produce numerous sudden conversion of strain energy into acoustic energy, which confirms this idea of multiple cracking.

For specimen UD-0 and CR-(0/90), the apparition of class A and $B$ corresponds to the yield point observed during monotonic and cyclic tensile loading. This confirms that this knee on the stress/strain curve does not only correspond to the non linear behaviour of the fibres, but also traduces the appearance of damage mechanisms at the composite scale. However, beyond this yield point, and before the appearance of class $C$ events, the Sentry Functions of specimens UD-0 and CR-(0/90) increases. This corresponds to the increase of tangent modulus observed on monotonic tensile curves between $0.3 \%$ and $0.4 \%$ of strain. This may be explained by macroscopic realignments of fibres and bundles at the composite scale, as well as the reorientation of cellulose microfibrils at the fibre scale.

Events of class $C$ are also observed for every kind of specimen. The existence of such events for specimens UD-90 and UD-45 exclude the hypothesis of fibre breakage. However, pulled-out fibres were noticed during macro and microscopic analyses of every specimen after failure. Thus for UD-90 and UD-45 configurations, fibre pull-outs could be attributed to class $C$. The number of hits corresponding to this class increases for specimen UD-0 and CR-(0/90), as well as the number of fibre pulled out noticed by macroscopic inspections of the failure fronts. However, the number of events of class $C$ increases drastically for specimen CR- $(+45 /-45)$. This phenomenon can be attributed to delamination. This damage mode appears to be predominant on this configuration. It is a global phenomenon that includes a lot of fibre/matrix friction and fibre/fibre friction. As a consequence, depending on the loading configuration, class $C$ may probably gather fibre pull-outs and delamination. This may explain the statistical spread observed for class $C$ in the different configurations.

The last class (D) does not exist for specimen UD-90 and UD-45. The occurrence of such events in specimen UD-0 and CR-(0/90) corresponds to an immediate increase of the number of hits recorded for all other classes. Moreover, the Sentry Functions decrease with the occurrence of the first class D events. It is usually followed by the complete failure of the specimen. As a consequence, it can be attributed to fibre and bundle failure. It is worth noticing that despite the high energy of these events, no severe discontinuities are observed on the Sentry functions. This is explained by the very small number of events of class $D$ with respect to all the other events that contribute to the drastic rise of the cumulative acoustic energy.

\section{Conclusion}

As a conclusion, a new thermoplastic composite reinforced with flax fibres was produced by an adapted liquid resin infusion process. Five types of specimens were prepared with different fibre orientations in order to emphasis particular damage mechanisms under uniaxial tensile loading. The mechanical tests were monitored by acoustic emission. AE data were processed with an unsupervised pattern recognition algorithm based on five classification parameters. Four classes of events were obtained. Their acoustic characteristics were studied in terms of average properties and statistical spread for every specimen and according to every classification parameter. On the first hand, microscopic observations were used to propose a correlation between the failure mechanisms observed in the composites and the AE classes obtained. On the other hand, the Sentry Function was used to consider at the same time the mechanical and acoustic activity of the 
material, and to comfort us in the correlation between damage mechanisms and acoustic emission classes. This study brought interesting considerations regarding the non linear behaviour of this flax/Elium composite. The AE classification procedure used in this work did not allow the identification of every damage mechanisms occurring during tensile tests. A more precise clustering may have been achieved by using other classification features, involving for example frequency analyses of the signals, which have rarely been performed for NFRP according to the literature. However, it revealed that the use of five temporal parameters seems to be sufficient to separate the main groups of events, which have the most noticeable consequences on the mechanical behaviour of the composite.

\section{Acknowledgments}

We are grateful for the financial support from the MATIERES project and the "Région Pays de la Loire". The authors also would like to thank Pierre Gerard from ARKEMA for his help with the processing of the Elium resin, as well as François Van Fleteren and Bruno Delier from LINEO for their support concerning the FlaxTape. The authors also thank Isabelle Gimenez from CTTM (Centre de Transfert de Technologie du Mans) for her help with microscopic observations.

\section{References}

[1] Faruk O, Bledzki AK, Fink HP, Sain M. Biocomposites reinforced with natural fibers: 2000-2010. Prog Polym Sci 2012;37:1552-96.

[2] Yan L, Chouw N, Jayaraman K. Flax fibre and its composites - a review. Compos Part B Eng 2014:56:296-317.

[3] Baley C, Bourmaud A. Average tensile properties of French elementary flax fibers. Mater Lett 2014;122:159-61.

[4] Lefeuvre A, Bourmaud A, Morvan C, Baley C. Elementary flax fibre tensile properties: correlation between stress-strain behaviour and fibre composition. Ind Crops Prod 2014;52:762-9.

[5] Dahmene F, Yaacoubi S, El Mountassir M. Acoustic emission of composites structures: story, success, and challenges. Phys Proc 2015;70:599-603.

[6] Maillet E, Baker C, Morscher GN, Pujar VV, Lemanski JR. Feasibility and limitations of damage identification in composite materials using acoustic emission. Compos Part A Appl Sci Manuf 2015;75:77-83.

[7] Huguet S. Application de classificateurs aux données d'émission acoustique: identification de la signature acoustique des mécanismes d'endommagement dans les composites à matrice polymère. 2002 Ph.D. Thesis. France: INSA de Lyon; 2002.

[8] Bourchak M, Farrow IR, Bond IP, Rowland CW, Menan F. Acoustic emission energy as a fatigue damage parameter for CFRP composites. Int J Fatigue 2007;29:457-70.

[9] Li L, Lomov SV, Yan X. Correlation of acoustic emission with optically observed damage in a glass epoxy woven laminate under tensile loading. Compos Struct 2015;123:45-53.

[10] Gutkin R, Green CJ, Vangrattanachai S, Pinho ST, Robinson P, Curtis PT. On acoustic emission for failure investigation in CFRP: pattern recognition and peak frequency analyses. Mech Syst Signal Process 2011;25:1393-407.

[11] de Groot PJ, Wijnen PAM, Janssen RBF. Real-time frequency determination of acoustic emission for different fracture mechanisms in carbon epoxy composites. Compos Sci Technol 1995;55:405-12.
[12] Sause MGR, Gribov A, Unwin AR, Horn S. Pattern recognition approach to identify natural clusters of acoustic emission signals. Pattern Recog Lett 2012;33:17-23

[13] De Rosa IM, Santulli C, Sarasini F. Acoustic emission for monitoring the mechanical behaviour of natural fibre composites: a literature review. Compos Part A Appl Sci Manuf 2009;40:1456-69.

[14] El Mahi A, Ben Salem I, Assarar M, Berbaboui R, Poilâne C, El Guerjouma R. Analyse par émission acoustique de l'endommagement des matériaux écocomposites. 10ème Congrès Français d'Acousitque 2010.

[15] Elouaer A, Aboura Z, Ayad R, Sabhi H, Elouaer A, Aboura Z, et al. Monitoring of fatigue damage in composites based fiber plant. Journées Nationale des Composites 2009.

[16] Kersani M, Lomov SV, van Vuure AW, Bouabdallah A, Verpoest I. Damage in flax epoxy quasi unidirectional woven laminates under quasi static tension. J Compos Mater 2015;49:403-13.

[17] Romhany C, Karger-Kocsis J, Czigany T. Tensile fracture and failure behavior of technical. J Appl Polym Sci 2003;90:3638-45.

[18] Bravo A, Toubal L, Koffi D, Erchiqui F. Characterization of tensile damage for a short birch fiber-reinforced polyethylene composite with acoustic emission. Int J Mater Sci 2013;3:79-89.

[19] Aslan M. Investigation of damage mechanism of flax fibre LPET commingled composites by acoustic emission. Compos Part B Eng 2013;54:289-97.

[20] Saeedifar M, Fotouhi M, Ahmadi Najafabadi M, Hosseini Toudeshky H, Minak G. Prediction of quasi-static delamination onset and growth in laminated composites by acoustic emission. Compos Part B Eng 2016;85:113-22.

21] Khalfallah M, Abbès B, Abbès F Guo YO Marcel V, Duval A, et al. Innovative flax tapes reinforced Acrodur biocomposites: a new alternative for automotive applications. Mater Des 2014;64:116-26.

[22] Baley C, Le Duigou A, Bourmaud A, Davies P. Influence of drying on the mechanical behaviour of flax fibres and their unidirectional composites. Compos Part A Appl Sci Manuf 2012;43:1226-33.

[23] ASTM D30309/D3039M-14: Standard test method for tensile properties of polymer matrix composite.

[24] Poilâne C, Cherif ZE, Richard F, Vivet A, Ben Doudou B, Chen J. Polymer reinforced by flax fibres as a viscoelastoplastic material. Compos Struct 2014;112:100-12

[25] Shah DU. Damage in biocomposites: stiffness evolution of aligned plant fibre composites during monotonic and cyclic fatigue loading. Compos Part A App Sci Manuf 2015.

26] Placet V Cissé O, Lamine Boubakar M. Nonlinear tensile behaviour of elementary hemp fibres. Part I: investigation of the possible origins using repeated progressive loading with in situ microscopic observations. Compos Part A Appl Sci Manuf 2014;56:319-27.

[27] Trivaudey F, Placet V, Guicheret-Retel V, Boubakar ML. Nonlinear tensile behaviour of elementary hemp fibres. Part II: modelling using an anisotropic viscoelastic constitutive law in a material rotating frame. Compos Part A Appl Sci Manuf 2015:68:346-55.

[28] Ashin Z, Rotem A. A fatigue failure criterion for fiber reinforced materials. ] Compos Mater 1973; 7:443-64.

[29] Likas A, Vlassis N, Verbeek J. The global k-means clustering algorithm. Pattern Recog 2003;36:451-61. http://dx.doi.org/10.1016/S0031-3203(02)00060-

[30] Milligan GW, Cooper MC. An examination of procedures for determining the number of clusters in a data set. Psychometrika 1985;50:159-79.

31] Bakhtiary Davijani AA, Hajikhani M, Ahmadi. Acoustic emission based on sentry function to monitor the initiation of delamination in composite materials. Mater Des 2011;32:3059-65.

[32] Selman E, Ghiami A, Alver N. Study of fracture evolution in FRP-strengthened reinforced concrete beam under cyclic load by acoustic emission technique: an integrated mechanical-acoustic energy approach. Constr Build Mater 2015;95:832-41.

[33] Chen Z, Li D, Li Y, Feng Q. Damage analysis of FRP/steel composite plates using acoustic emission. Pac Sci Rev 2015;16:112-9. 